\title{
Modelo de informação da construção para o projeto baseado em desempenho: caracterização e processo
}

\author{
The building information model in performance-based \\ design: characterisation and process
}

\section{Giovanna Tomczinski Novellini Brígitte Regina Coeli Ruschel}

\section{Resumo \\ A}

preocupação com o desempenho das edificações tem ganhado destaque no Brasil e originado transformações significativas no setor de arquitetura, engenharia e construção (AEC). Pesquisas recentes propõem a integração das análises de desempenho às etapas iniciais do processo de projeto, a fim de obter o melhor desempenho final da edificação. Nesse sentido, escolher o conjunto de soluções adequadas e formas computacionais de desenvolvê-las é uma tarefa de alta complexidade e responsabilidade. Esta pesquisa investiga a compreensão da técnica e utilização de instrumentos de avaliação computacional de desempenho durante as etapas iniciais do projeto. Para isso, desenvolve uma pesquisa exploratória em que evidencia relações entre requisitos de desempenho, avaliação computacional e a tomada de decisão na promoção de soluções em prol da melhoria da qualidade final do projeto. Através do estudo de campo foi possível elucidar o modelo de informação e identificar os parâmetros que entram em confronto direto por serem compartilhados por um ou mais desempenhos. Pode-se ainda analisar a influência entre os desempenhos, tendo como resultado a proposição de uma metodologia de sequenciamento das simulações.

Palavras-chaves: Modelagem da Informação da Construção. Avaliação de desempenho. Simulação computacional. Processo de projeto.

\begin{abstract}
The concern with building performance has gained prominence in Brazil and generated significant changes in the Architecture, Engineering and Construction (AEC) sector. Recent research studies have proposed the integration of performance analysis into the early stages of the design process, aiming to achievethe best final building performance. Choosing an adequate set of solutions and computer aided ways to develop them is a highly complex task, involving great responsibility. This study investigates the understanding of the technique and

utilization of performance computational evaluation tools in the early stages of the design process. Hence, an exploratory study was undertaken in order to clarify the relationships between performance requirements, computer aided evaluation and decision-making in the promotion of solutions aimed at improving the final quality of the project. Through a field study, it was possible elucidate the information model and identify the parameters that come into direct confrontation with each other as they are being shared by one or more performances. The influence between the performances can be also analysed, resulting in the proposition of a simulation sequence methodology.
\end{abstract}

Giovanna Tomczinski Novellini Brígitte Universidade Estadual de Campinas Campinas - SP - Brasil

Regina Coeli Ruschel Universidade Estadual de Campinas Campinas - SP - Brasil

Recebido em 18/02/16 Aceito em 05/08/16
Keywords: Building Information Modeling. Performance evaluation. Computational simulation. Design process. 


\section{Introdução}

O desempenho das edificações tem ganhado destaque no cenário nacional por ter originado transformações significativas no setor de arquitetura, engenharia e construção (AEC). Nesse sentido, tal preocupação eleva a complexidade e a responsabilidade do ato de projetar em busca da máxima eficiência energética, sem comprometer outras prerrogativas inerentes ao projeto.

Em contrapartida, pesquisas nacionais focadas na gestão do processo de projeto destacam a necessidade de aplicação de uma visão sistêmica entre as diversas variáveis que compõem a solução final do projeto (MELHADO, 2001; FABRICIO, 2002; ROMANO, 2003). No âmbito do desempenho ambiental, Marsh (1997), Kalay (1999), Soebarto e Williamson (2001), Giannantoni et al. (2005), Struck e Hensen (2007), Alucci (2007) e Petersen e Svendsen (2010) apresentam metodologias para análise conjunta dos parâmetros de projeto relacionados ao desempenho ambiental, suscetíveis ao confronto direto, com o auxílio das ferramentas de simulação e avaliação digital em busca da solução mais adequada.

Apesar de estudos acerca dos instrumentos de avaliação com o objetivo de flexibilizar e auxiliar as decisões dos projetistas terem sido iniciados na década de 70, ainda hoje as ferramentas não conseguem agregar uma real reestruturação no processo de projeto, muitas vezes por apresentarem dificuldade de utilização, e ainda por vezes pelo próprio desconhecimento de sua existência. Os resultados levantados por diversas pesquisas apontam para o desinteresse, a dificuldade de aplicação pelos projetistas e a insatisfação dos resultados obtidos (HOLM, 1993; MATHEWS; RICHARD, 1993; ATTIA et al., 2009; ATTIA, 2010).

Sendo assim, esta pesquisa avaliou a similaridade dos modelos necessários no processamento de cada simulação entre as disciplinas Acústica, Termoenergética, Luminosa, Conservação de Água, Acessibilidade e Ciclo de Vida, para finalmente tornar possível a realização das diferentes simulações a partir da construção de um único modelo, a qual diminui o risco de perder soluções adotadas durante o processo e da falta de identificação da influência de decisões tomadas ante o conjunto do projeto.

Como apontado por Papamichael (1991), o processo de projeto é caracterizado por ser evolutivo, multidisciplinar, apresentar multicritérios e multissoluções. Sendo assim, qualquer equivoco durante a modelagem pode resultar em soluções ineficazes ao projeto.
O objetivo da pesquisa foi caracterizar as informações agregadas ao modelo, explicitando seus parâmetros, influências e sequenciamento das simulações, visando à integração de análises de desempenho no processo de projeto. O estudo considerou na fase de concepção estudos para o projeto de implantação, para habitação de interesse social (HIS). Os desempenhos considerados foram térmico, acústico e luminoso, da conservação de recursos materiais, da conservação de água e acessibilidade.

Dessa forma, busca-se a compreensão da técnica e da utilização de instrumentos de simulação computacional de desempenhos durante as etapas iniciais do projeto, o que contribui positivamente para a eficiência do edifício. Avalia-se ser também a interoperabilidade entre os softwares de simulação fundamental para a eficácia da análise integrada de desempenho e retroalimentação do processo de projeto.

Esta pesquisa foi desenvolvida no âmbito de um mestrado, no Programa de Pós-Graduação em Arquitetura, Tecnologia e Cidade da Faculdade de Engenharia Civil, Arquitetura e Urbanismo da Universidade Estadual de Campinas. O mestrado realizou-se no contexto da Rede Cooperativa de Pesquisa em Tecnologias da Informação de Comunicação Aplicadas à Construção de Habitação de Interesse Social, vinculada à agência Financiadora de Estudos e Projetos (Finep). A Rede Cooperativa Finep-Thichis congregou entre 2012 e 2015 pesquisadores brasileiros referência em tecnologia da informação aplicada à arquitetura, engenharia e construção visando ao desenvolvimento de soluções inovadoras na habitação de interesse social, com destaque para Building Information Modeling (BIM) e outras soluções para suporte ao processo de gerenciamento de projetos, simulação de desempenho e operação de edificações.

\section{Fundamentação}

Novas exigências fazem com que os projetistas se deparem com a necessidade de buscar soluções integradas capazes de atingir as metas de desempenho estipuladas. Entretanto, sabe-se que muitas soluções são interdisciplinares e requerem um ambiente cada vez mais colaborativo nas tomadas de decisão ainda nas etapas iniciais do projeto. Nesse sentido a tecnologia da informação surge como uma ferramenta capaz de auxiliar os projetistas a criar um ambiente integrado para o desenvolvimento do projeto, testar as propostas e validar soluções mais adequadas ao conjunto da 
edificação, antevendo e predizendo o desempenho em cada uma das alternativas.

Tecnologia da informação e comunicação (TIC) é um termo geral que se refere a toda tecnologia utilizada para processar, armazenar e distribuir informação (WILLIAN; SAWYER, 2007). A TIC inclui dois tipos de tecnologia: computacional e de comunicação. A tecnologia computacional faz uso do computador como uma máquina multiúso e programável que aceita dados e os processa, gerando a informação que utilizamos. A tecnologia da comunicação consiste em equipamentos e sistemas para a comunicação a distância.

Com relação à TIC aplicada ao processo de projeto, interessa-nos particularmente os aplicativos que dão suporte ao processamento da informação e o fluxo de informações gerado entre múltiplos aplicativos. Esses aplicativos são os de produtividade e os específicos. Entre os aplicativos específicos encontram-se os relativos a gestão de projeto, projeto auxiliado por computador, modelagem da informação na construção e simulação.

Como é sabido, o processo de projeto de um edifício é composto de diversas fases e diferentes intervenientes (projetistas, construtores, financiadores, usuários, entre outros). Isso reflete a complexidade que a indústria da AEC apresenta, que também advém do caráter do artefato arquitetônico e do processo de decisão associado.

Os principais fatores que definem a complexidade no projeto são: alto grau de interação entre as partes; contínuas mudanças e evolução; alto grau de interação não linear com o ambiente; e dificuldade de execução de atividades individuais que compõem um processo (WOOD; GIDADO, 2008). Portanto, existe interdependência entre as diferentes dimensões do projeto, as quais estão entrelaçadas e diretamente relacionadas ao desempenho do edifício final (JU; NING; PAN, 2016).

Ao considerar a complexidade do processo de projeto, torna-se imprescindível sua gestão e coordenação. Isso ocorre a fim de possibilitar a sistematização e facilitar o manuseio de informações relativas a uma infinidade de variáveis que o compõem e que se interconectam em sistemas complexos. Nesse sentido a TI auxilia o processo de projeto por permitir que um número maior de informações, mais detalhadas e completas, tanto internas quanto externas à empresa, seja acessado e analisado em menos tempo.

De acordo com Nascimento e Santos (2003), a informação deve ser compartilhada por todos os agentes, e para isso devem ser utilizados mecanismos de comunicação com ferramentas para acesso às informações por toda a equipe. A principal utilização da informação é para a tomada de decisão. Por isso, a qualidade da informação pode determinar o acerto das decisões tomadas.

As contribuições da TI ao setor da construção, no mundo, tiveram início na década de 80 com a introdução da automatização de tarefas específicas por meio do computer aided drawing (desenho auxiliado por computador), que agregaram rapidez e eficiência na realização das atividades. Ruschel (2009) apresenta a evolução dos sistemas Cumputer Aided Design (CAD) a partir do suporte oferecido ao desenho técnico através das ferramentas de desenho bidimensional (CAD 2D), perpassando pelos recursos tridimensionais (CAD 3D), cuja necessidade de facilitar a modelagem fez surgir modelos 3D parametrizados. A estes modelos foi-se aos poucos agregando informações não gráficas como tempo (CAD 4D), custo e material, entre outras, e o CAD evoluiu finalmente para $\mathrm{nD}$.

Destaca-se a necessidade da precisão na representação da informação de AEC de forma integrada e inteligente, como propulsora para a interoperabilidade entre sistemas CAD e todo o ferramental computacional participante do ciclo de vida da edificação. Essa mudança direcionou o surgimento do conceito BIM.

Eastman et al. (2008, p. 467) define BIM como

[...] a verb or adjective phrase to describe
tools, processes and technologies that are
facilitated by digital, machine-readable
documentation about a building, its
performance, its planning, its construction
and later its operation [...]

Através do BIM, um modelo tridimensional preciso do edifício é construído digitalmente com o uso de informações paramétricas. As informações paramétricas tornam os objetos "inteligentes". Para Smith e Tardif (2009), a principal característica do BIM que o distingue das tecnologias de projeto que o precedem não é a modelagem tridimensional, mas a informação sistematizada, que pode ser organizada, definida e permutável.

A simulação, através da ferramenta computacional, para avaliação das decisões projetuais existe tanto no contexto CAD como no contexto BIM; a diferença está na ênfase do segundo no reúso da informação por meio da interoperabilidade. Como um mesmo projeto deve ser submetido a diferentes simulações, portanto, a diferentes aplicativos, o modelo final deve conter todas as informações 
necessárias às diferentes análises, e, não obstante, os softwares devem possuir um formato de troca mutuamente suportado. De acordo com Malkawi (2005), essa necessidade tornou possível o desenvolvimento de ambientes e plataformas que conseguem a integração das análises do projeto com base em representações semânticas que suportam a interação de dados dos objetos. O principal formato utilizado hoje para a troca de dados é o Industry Foundation Classes (IFC), capaz de manter as associações entre o modelo completo e o simulado. Todavia, Pazlar e Turk (2008) e Andrade e Ruschel (2009) demonstraram que o IFC não era robusto o suficiente para transportar dados com a qualidade do modelo original, por apresentar perdas de dados durante a migração entre aplicativos.

Apesar de relacionado a uma leitura contemporânea, o verbo "simular" é um termo associado à antiga arte de construção do modelo, aplicada a algumas formas muito variadas de construção dele, que vão desde pinturas renascentistas e da escultura de modelos em escala a modelos computacionais de processos cognitivos. Segundo Naylor et al. (1966), "Simulation is, therefore, essentially a technique that involves setting up a model of a real situation and then performing experiments on the model.".

Vale ressaltar que o uso moderno da palavra traça sua origem na obra de von Neumann e Ulam no final dos anos 1940, quando apresentaram a análise de Monte Carlo, que envolveu a solução de um problema não matemático probabilístico através da simulação de um processo estocástico que tem momentos ou distribuições de probabilidade que satisfaçam as relações matemáticas do problema probabilístico. Entretanto foi somente com o advento do computador de alta velocidade, no início da década de 50, que a simulação assumiu outro caráter, através de experiências com modelos matemáticos de um computador, tornando possível a realização de experimentos controlados em áreas da ciência que não o faziam (CHWIF; MEDINA, 2010). Nessa etapa podemos observar uma primeira classificação do termo "simulação" em duas categorias distintas: a que necessita de um computador para ser realizada; e outra que não.

Existem ainda vários termos relacionados à simulação como sistema e modelo, entre os vários tipos de simulação. Conforme Chwif e Medina (2010), quando pensamos em simular algo, queremos obviamente simular algum sistema, um agrupamento de partes que operam juntas, visando a um objetivo em comum. Um sistema sempre pressupõe uma interação causa-efeito entre as partes que o compõem. Para que tais partes e, principalmente, para que as interações entre as partes sejam identificadas, o objetivo do sistema deve ser conhecido com clareza.

As ferramentas de simulação de avaliação do desempenho surgem da intenção de fazer entender e analisar o comportamento do edifício, desde sua concepção a sua demolição. Muitos profissionais são envolvidos, uma vez que a diversidade de análises requer proporcionalmente agentes com conhecimentos específicos, pois diferentes problemas requerem diferentes simulações.

Essa diversidade de simulações para a compreensão do quadro geral do projeto torna extremamente necessária a coordenação e a gestão das informações do modelo único, uma vez que ainda hoje as simulações são realizadas de maneira isolada, e as ferramentas não conseguem atender à integração dos modelos resultantes, seja por não agregarem diferentes simulações, seja por não fornecerem mecanismos adequados à interoperabilidade entre as ferramentas disponíveis (CLARKE; HENSEN, 2015).

Desde a década de 80 acredita-se que a simulação computacional através da modelagem é capaz de fornecer uma avaliação rigorosa e detalhada do projeto energético do edifício (HUI, 1998). Entretanto, sua utilização sempre esteve atrelada a profissionais cada vez mais qualificados e especializados, uma vez que as ferramentas, apesar do grande avanço conquistado, ainda não apresentam uma interface naturalmente amistosa aos usuários, que por vezes desconhecem suas propriedades e limitações (HOLM, 1993; MATHEWS; RICHARD, 1993).

Bartak et al. (2003) ressaltam a importância do conhecimento e da utilização correta da simulação como prática para garantir competitividade no mercado de AEC. Atualmente podemos identificar no mercado imobiliário a corrida por certificações e o apelo associado à sustentabilidade como propulsores da retomada do interesse por soluções diferenciadas, maior inovação e, portanto, retomada da utilização da ferramenta de simulação pelos profissionais da área.

Diante do grande crescimento de opções de softwares, emerge a necessidade de selecionar entre a grande variedade e diversidade, as melhores aplicações e suas limitações, inspirando assim alguns cuidados que devem ser levados em conta na identificação e utilização das ferramentas disponíveis. Isso posto, salientamos que uma ferramenta de simulação de qualidade inferior nas mãos de um engenheiro consciente de suas características e capacidades é superior à melhor ferramenta de simulação nas mãos de um 
engenheiro pouco familiarizado (WALTZ, $1992^{1}$ apud WESTPHAL, 2007).

\section{Método}

Para melhor coerência entre a teoria e a prática desenvolveu-se uma pesquisa exploratória em que se buscou, por meio do estudo de campo, familiarizar-se com o problema, através de levantamento bibliográfico, entrevistas com os especialistas e aplicação de questionário on-line com foco nas relações entre requisitos de desempenho, avaliação computacional e tomada de decisão na promoção de soluções em prol da melhoria da qualidade final do projeto. O estudo de campo foi realizado em cinco etapas:

(a) definição do domínio do problema;

(b) preparação para a coleta de dados;

(c) coleta de dados;

(d) análise dos dados; e

(e) síntese dos produtos.

A primeira etapa foi constituída pelo domínio do problema. Nela se buscou apresentar a importância das avaliações de desempenho no processo de projeto de edificações ante as inovações tecnológicas de suporte à simulação. Identificou-se a importância das ferramentas de simulação e avaliação do desempenho, destacando-se Holm (1993), Mathews e Richard (1993), Hui (1998), Bartak et al. (2003), Malkawi e Augenbroe (2004), Crawley (2008), Yezioro et al. (2008), Attia et al. (2009), Attia (2010) e Lobos e Trebilcock (2014).

Como terminologia multidimensional, o desempenho assume neste trabalho o conceito consolidado por Gibson (1982), o qual corresponde à prática de pensar e trabalhar em termos dos fins, e não dos meios. A integração das ferramentas ao fluxo do projeto baseado em desempenho proposto por Petersen e Svendesen (2010) é ideal por reduzir as interações que podem ocorrer até o encontro da proposta que atenda aos pré-requisitos estabelecidos. Como a abordagem da edificação deve ser sistêmica, a Figura 1 apresenta a relação entre os elementos metodológicos e o fluxo do projeto, e integra os desempenhos abordados nesta pesquisa: acústico (Ac.), térmico (Te.), luminoso (Lm.), funcional com foco na acessibilidade (Ace.); e em sustentabilidade no parâmetro de consumo de recursos: água (CsAg.) e materiais (CsMt.).
A ilustração apresenta a solução (proposta de projeto) como produto da dinâmica implícita entre análise, síntese e avaliação, levando em consideração os requisitos do desempenho desejado. Esse produto é representado num modelo submetido a diversas simulações (avaliações de desempenho) que ocorrem em separado (em paralelo ou sequencial), sendo necessários $n$ ciclos de simulações, para que através da variação de parâmetros surjam novas propostas, até que o modelo alcance o desempenho desejável.

$\mathrm{Na}$ segunda etapa, de preparação para a coleta, foram definidas as estratégias para a coleta e elaborados os instrumentos que constituíram a compreensão da prática na pesquisa: entrevistas e questionário. Uma entrevista permite a interação do pesquisador com o entrevistado, de forma a captar atitudes, reações e, principalmente, sinais não verbais. Neste trabalho optou-se pela entrevista semiestruturada, por oferecer ao pesquisador maior flexibilidade, já que permite intervenções de acordo com seu desenvolvimento. O roteiro apresentado no Quadro 1 foi direcionado a levantar diretrizes de desempenho nas etapas iniciais de projeto.

Quanto ao questionário, optou-se por esse tipo de instrumento por ser capaz de minimizar as distorções das respostas registradas, mediante o distanciamento entre o pesquisador e o informante que o responde, e por permitir que os dados sejam disponibilizados para análise em um período relativamente curto. Elaborado a partir da adaptação do trabalho desenvolvido por Attia (2010), foi organizado em seis blocos temáticos, apresentados a seguir, no Quadro 2.

$\mathrm{Na}$ terceira etapa da pesquisa, a coleta de dados, foram realizadas as entrevistas planejadas (Quadro 1) e a aplicação do questionário (Quadro 2). 
Figura 1 - Fluxo de projeto proposto pela pesquisa

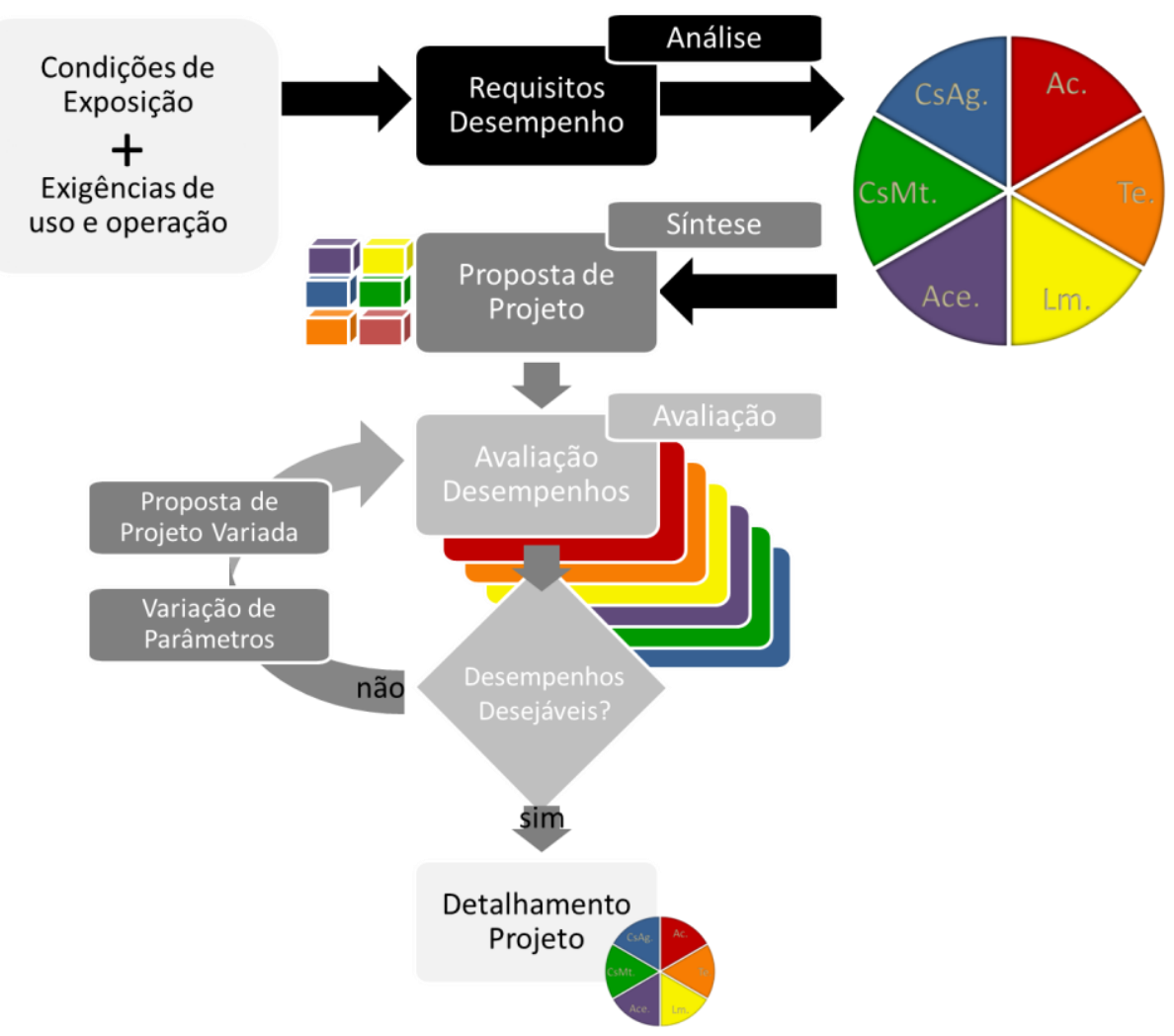

LEGENDA: Ac. Acústico; Te. Térmico; Lm. Luminoso; Ace. Acessibilidade; CsMt Consumo Material; CsAg. Consumo Água

Fonte: Brígitte (2013, p. 70).

\section{Quadro 1 - Roteiro das entrevistas}

\section{Projeto x Desempenho}

Delimitação do Problema: Identificação do escopo na etapa de concepção.

Identificação dos Requisitos: Levantamento dos critérios e parâmetros.

\section{Perguntas:}

a. Qual é o escopo de sua especialidade no projeto da edificação HIS ainda nas fases iniciais de estudos

de massa/implantação?

b. Quais critérios e parâmetros de sua especialidade são abordados na etapa de concepção?

\section{Multidesempenho}

Estabelecer a relação entre desempenhos: Identificação das interferências entre desempenhos.

\section{Pergunta:}

Existe alguma interferência entre o desempenho de sua especialidade e outro?

3. Desempenho x Avaliação

Delimitação do Problema: Identificação do processo de avaliação na etapa de concepção.

\section{Pergunta:}

Qual o método de avaliação, análise de projeto, utilizado hoje?

\section{Avaliação x Ferramenta Computacional}

Identificação das Ferramentas: Levantamento das ferramentas computacionais de avaliação.

\section{Pergunta:}

Existe alguma ferramenta computacional que auxilie este processo?

Fonte: adaptado de Brígitte (2013, p. 71). 
Quadro 2 - Organização do questionário

Bloco Temático I: (a) Identificação do respondente; (b) Perfil dos softwares de modelagem e simulação; (c) Perfil das simulações

Perguntas:

a. Formação (arquitetura; engenharia; outra)

b1. Dos softwares de modelagem CAD/3D, qual/quais você utiliza? (Viz; Rhino; FormZ; Maya;

ArchiCad; Bentley Archiecture; Revit Suite; Sketchup; Digital Project; AutoCAD; outros).

b2. Das ferramentas de análise/simulação, qual/quais você utiliza? (Ecotect; ESP-r; Design Builder;

gBXML; eQUEST; Energy-10; Energy+; Radiance; Odeon; Bastian; EnvestII; Solibri; outros).

c1. Quais tipologias você frequentemente simula? (residencial; institucional; comercial; serviços; outras).

c2. Na maior parte das vezes você simula: (ambientes externos; ambientes internos; ambos).

c3. Na maior parte das vezes você simula: (iluminação natural/artificial; uso de água (estimativa e custo); ciclo de vida; desempenho acústico; desempenho térmico; eficiência energética; desempenho funcional; sistemas HVAC; outros).

Bloco Temático II: Identificação dos critérios e características nas ferramentas

Perguntas:

a1. Quais critérios de usabilidade/gerenciamento das informações são importantes em uma ferramenta de simulação de desempenho? (interface amistosa aos usuários; facilidade de utilização/curto período de curva de aprendizado; fácil navegação e organização das informações; modelabilidade; representação gráfica dos resultados; facilidade de introduzir dados de entrada; outros).

a2. Quanto à capacitação e utilização, quais itens são importantes? (treinamentos especializados; custo das ferramentas; disponibilidade/facilidade de aquisição por estudantes; tempo de aprendizado necessário; outros).

a3. Você considera importante (criação de relatórios comparativos entre alternativas; controle de qualidade dos dados de entrada; pressupostos e valores padrão dos dados de entrada; armazenamento de dados flexíveis e passíveis de customização; simplicidade na entrada dos dados, revisão e modificação dos parâmetros; outros).

a4. Que outras características deveriam ser consideradas quanto à usabilidade e gerenciamento das informações?

Bloco Temático III: Integração à base de dados e integração das ferramentas no processo de projeto Perguntas:

a1. São fundamentais para a simulação do desempenho da edificação? (parâmetros de conformidades normativas; parâmetros de conformidade de sistemas de certificação (LEED, Aqua); dados climáticos; bibliografia extensiva de componentes e sistemas da construção; suporte e treinamento on-line das ferramentas; outros).

a2. São fundamentais para a ferramenta de simulação: (fornecer análises rápidas de suporte à tomada de decisão; permitir analisar a incerteza de parâmetros essenciais; analisar as características climáticas e fornecer estratégias de projeto; compreender mais de um estágio das fases do projeto; outros).

Bloco Temático IV: Assertividade e habilidade de simular componentes complexos

Perguntas:

a1. Qual critério de assertividade é fundamental a uma ferramenta de simulação? (resultados precisos e reais; validade das simulações; controle das incertezas; alta resolução gráfica do modelo).

a2. Quanto à habilidade de simular componentes complexos é fundamental (permitir complexas estratégias de projeto; simular energia renovável; avaliar emissões associadas à energia de consumo, permitir avaliar custos do consumo de energia e do ciclo de vida; permitir simulações de diferentes tipologias de edificação).

Bloco Temático V: Interoperabilidade

\section{Perguntas:}

a1. Quais recursos são importantes para a utilização de ferramentas de simulação?

(importaçãolexportação entre programas CAD; importaçãolexportação entre programas BIM;

importação/exportação entre programas de simulação; capacidade de simulação de diferentes

desempenhos ante o mesmo modelo).

Bloco Temático VI: Identificação do grau de importância

\section{Pergunta:}

a. Qual característica você considera mais importante na escolha de uma ferramenta de simulação?

(usabilidadel gerenciamento das informações; integração com base de dados e das ferramentas ao

processo de projeto; assertividade e habilidade de simular componentes complexos; interoperabilidade).

Fonte: adaptado de Brígitte (2013, p. 71-74). 
As entrevistas foram realizadas dentro de um grupo específico, restrito aos professores pesquisadores da Faculdade de Engenharia, Arquitetura e Urbanismo da Unicamp que participavam da Rede Cooperativa Finep-Tichis. A equipe de pesquisa envolvida investigava o desempenho ambiental (acústico, térmico, luminoso), o consumo de água, o consumo de materiais (relacionados a quesitos de sustentabilidade) e a acessibilidade (relacionada a questões funcionais) na fase de concepção de projeto e no projeto de implantação em específico de maneira isolada. Dessa forma, esta pesquisa teve caráter integrador com ênfase na fase de avaliação das soluções de projeto. Insere-se aí a definição dos desempenhos considerados e dos especialistas envolvidos. Foi acrescido o especialista em desempenho luminoso da mesma universidade.

Inicialmente foi realizada uma sessão individual, seguindo o roteiro apesentado no Quadro 1, com cada um dos especialistas selecionados objetivando coletar informações referentes ao conhecimento utilizado durante o momento de implantação do projeto de HIS. Todos foram questionados quanto aos cuidados com o desempenho de sua especialidade, especialmente na fase conceitual da concepção do projeto, em que são definidas as principais características da edificação, como orientação, implantação, volumetria, distribuição espacial, entre outras. Após a realização da análise e a interpretação dos aspectos mais relevantes identificados, foi realizada uma nova entrevista com cada especialista para esclarecer as questões que permaneciam em aberto e, principalmente, para aprofundar o conhecimento.

A aplicação do questionário "Instrumentos de avaliação computacional de desempenho ambiental e acessibilidade no projeto de edificações", apresentado no Quadro 2, foi realizada mediante distribuição no grupo de discussão sobre Conforto Ambiental e Eficiência Energética ${ }^{2}$ da Associação Nacional de Tecnologia no Ambiente Construído (Antac). Esse levantamento com um grupo diverso e amplo de especialista objetivou diversificar a percepção de questões tecnológicas associadas ao tema, além da do grupo de especialistas envolvidos nas entrevistas. O questionário esteve disponível (on-line) entre os meses de março e abril de 2012. Durante esse período foi respondido por 38 pessoas. O perfil da amostra é predominantemente composto de arquitetos (76\%), seguidos de engenheiros (16\%) e complementada por profissionais de outras formações $(8 \%)$.

${ }^{2}$ Contato: <confortoambiental@ufrn.br>.
A quarta etapa, de análise dos dados, objetivou sumariar as observações. Para isso, os dados coletados nas entrevistas e nos questionários foram seguidos de análise formal do conteúdo, através da organização do material, descrição analítica dos dados (codificação, classificação e categorização) e interpretação referencial.

Além do estudo de campo, este estudo também realizou uma pesquisa experimental para validar os resultados encontrados, em especial os relativos ao sequenciamento das simulações de desempenho na fase de síntese das soluções. Entretanto, esse trabalho não é aqui incluído por fugir do escopo delimitado para este artigo - o detalhamento da pesquisa experimental é apresentado em Brígitte (2013).

\section{Análise e interpretação dos dados}

A seguir apresentam-se os resultados do estudo de campo envolvendo tanto o levantamento referente à utilização de instrumentos de avaliação computacional de desempenho como as entrevistas realizadas com especialistas. As entrevistas com os especialistas enfatizaram a fase de concepção arquitetônica para HIS, especificamente o projeto de implantação.

\section{Instrumentos de avaliação computacional de desempenho}

Os resultados apresentados a seguir ilustram como os instrumentos de avaliação computacional podem ser aplicados no processo de projeto. O levantamento não teve a intenção de traçar um panorama, mas sim vislumbrar e levantar alguns pontos de reflexão associados ao tema desta pesquisa. Nesse sentido, os resultados nas Figuras 2 e 3 são apresentados não de forma absoluta (quantitativa), mas relativa (qualitativa), em que a representatividade é atribuída pelo tamanho da fonte, ou seja, quanto mais citada, maior sua representação. Nos resultados obtidos, para as questões do Bloco Temático I (voltado ao perfil da simulação) (Quadro 2), procurou-se identificar primeiramente o que é submetido e quais os tipos de simulações realizadas, e posteriormente como é realizado o processo da simulação. A Figura 2 ilustra a relação entre as tipologias e os ambientes simulados, bem como os tipos de simulações frequentemente realizadas. Podemos nessa ilustração observar o destaque para as avaliações de iluminação e termoenergéticas em ambientes residenciais internos.

Já a Figura 3 apresenta o processo de como as simulações são realizadas. Com relação às 
ferramentas de análise de desempenho, a maior parte da amostra informou utilizar ferramentas diferentes das que estavam apresentadas no questionário. Essa informação supõe que a maior parte das simulações ocorre nos centros de pesquisa e ensino, e utiliza ferramentas desenvolvidas na academia, assim como aponta a literatura (ATTIA, 2010).

Com relação à percepção da aplicação das ferramentas de simulação durante o projeto, a grande maioria concorda que tais instrumentos são capazes, ainda durante a fase cognitiva, de promover inovação de soluções e melhoria da qualidade do projeto. Os especialistas participantes desse levantamento concentram a utilização das ferramentas em prol de testes e avaliação de soluções, como auxílio na tomada de decisão, pela antecipação de conflitos e possibilidade de diminuição dos erros. A maior assertividade das soluções aparece por último, refletindo ainda a necessidade de o usuário interagir com os resultados, uma vez que as ferramentas apresentam o resultado da solução proposta, e não a proposta da melhor solução.

Podemos observar através da Figura 4 as características nas ferramentas de simulação mais valorizadas e almejadas pelos especialistas que participaram do levantamento. $\mathrm{O}$ aspecto de interoperabilidade de maior importância para os especialistas foi importação e exportação de dados entre programas. Em termos de usabilidade e gerenciamento das informações destacaram-se a demanda por simplicidade na entrada de dados, a revisão e modificação dos dados de entrada e os parâmetros associados nos programas de simulação de desempenho. Quanto à integração das bases de dados e às ferramentas de desenvolvimento de projeto, o desejo maior é por base de dados climáticos contextualizadas. Finalmente, quanto à assertividade e habilidade de simular componentes complexos, deseja-se poder variar entre diferentes tipologias de edificação.

Figura 2 - Características das simulações

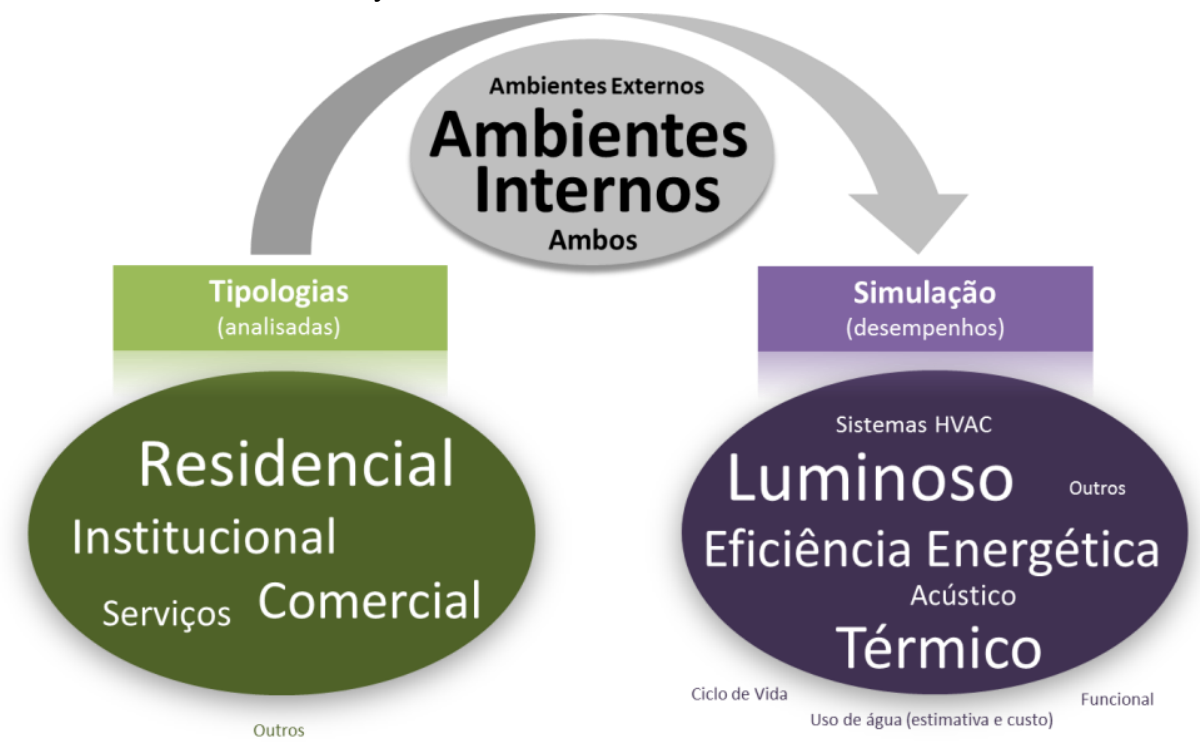

Fonte: Brígitte (2013, p. 88). 
Figura 3 - Ferramentas utilizadas nas simulações e tipos de entrada/saída dos dados

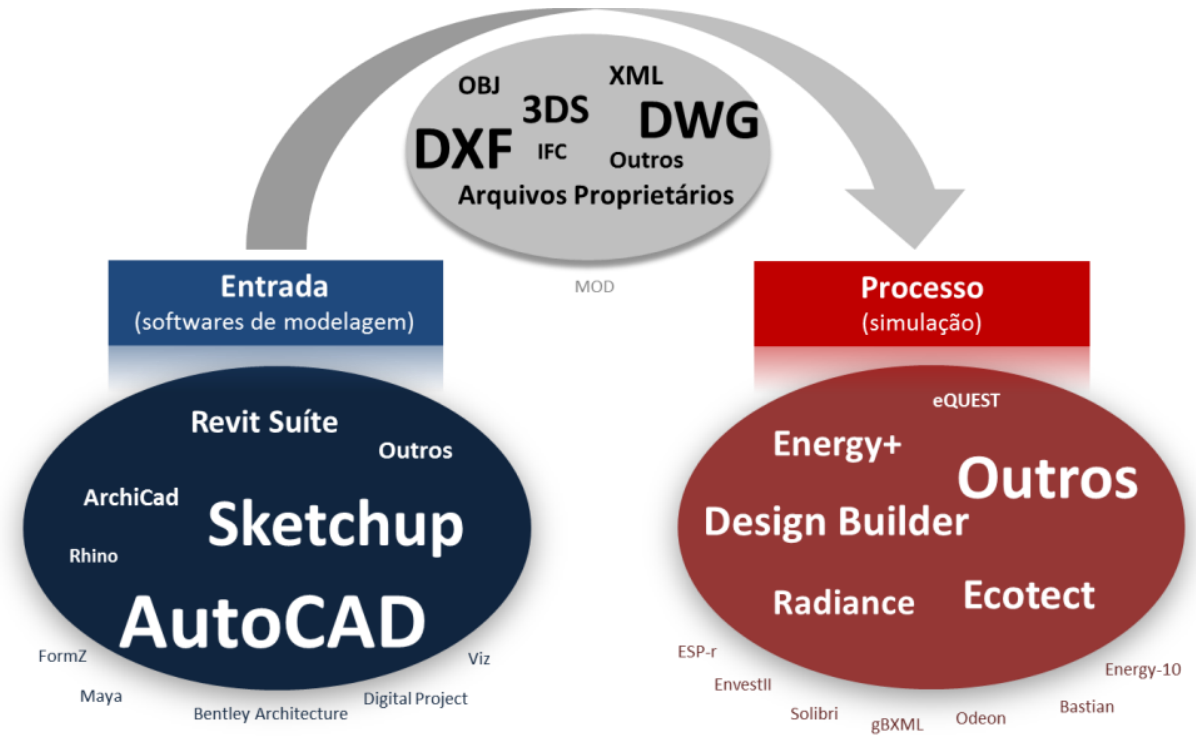

Fonte: Brígitte (2013, p. 88).

Figura 4 - Ferramentas de simulação: perfil das características mais valorizadas e almejadas

Assertividade e Habilidade de Simular Componentes Complexos

avaliação de emissões associadas à energia de consumo (11\%)

alta resolução do modelo (14\%)

simulação de energia renovável (19\%)

controle de incertezas (30\%)

avaliação do custo do consumo de energia e

do ciclo de vida (35\%)

resultados precisos e reais (48\%)

validade das simulações (65\%)

permitam estratégias complexas (62\%)

simular diferentes tipologias de edificação (70\%)

Interoperabilidade

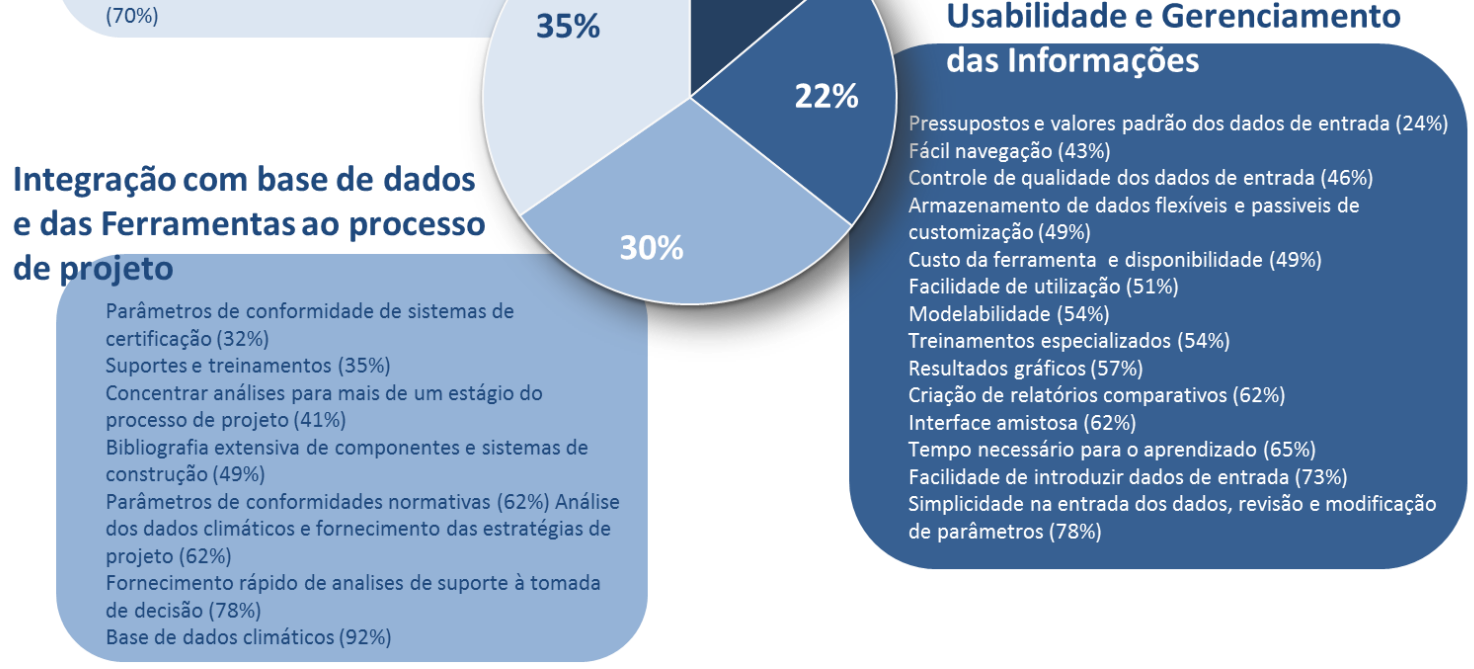

Fonte: Brígitte (2013, p. 89).

\section{Processo de projeto e a avaliação de desempenho}

Os resultados a seguir identificam os parâmetros, influências, métodos e ferramentas de avaliação computacional abordados nesta pesquisa. Apresenta-se conforme o roteiro proposto (Quadro 1). 


\section{Projeto versus desempenho}

A partir das entrevistas, identificaram-se os termos que melhor caracterizavam os parâmetros necessários para a avaliação do desempenho de sua especialidade na fase de concepção arquitetônica, especificamente considerando o projeto de implantação de conjuntos habitacionais (Tabela 1, primeira coluna). Identificou-se a recorrência ou não desses termos entre as entrevistas (Tabela 1, colunas 2-7), em que a ocorrência é identificada por "1" e a não ocorrência é identificada por "0". Dessa análise extraiu-se o conjunto global de fatores de influência (parâmetros de avaliação) (Tabela 1, última linha) e seu reúso entre escopos diferenciados de desempenhos (Tabela 1, última coluna à direita).

Essa análise possibilitou o mapeamento dos parâmetros mínimos necessários ao modelo, base de múltiplas análises. O resultado do modelo integrado é apresentado na Figura 5. Nessa ilustração pode-se identificar como informações mais reutilizadas, representando o modelo de informação mínimo e o mais reutilizado entre simulações, os materiais, a geometria e a volumetria. Em seguida, as informações sobre as aberturas, a orientação e o entorno. Outra leitura importante reflete o consumo de água como o que menos compartilha seus parâmetros, enquanto o consumo de materiais, apesar de apresentar o menor número de parâmetros, é o que mais compartilha. Isso pode sugerir uma elevada influência sobre os demais desempenhos, tornando a especificação do material fundamental no processo de projeto. Nesse caso podemos observar a necessidade de antecipar essa especificação, tomar como partido o que muitas vezes é decidido apenas em fases mais avançadas do projeto, como no detalhamento.

Tabela 1 - Parâmetros de avaliação apontados pelos especialistas

\begin{tabular}{|c|c|c|c|c|c|c|c|}
\hline $\begin{array}{c}\text { PARÂMETROS NECESSÁRIOS PARA } \\
\text { AVALIAÇÃO }\end{array}$ & Ac. & Te. & Lm. & Ace. & $\begin{array}{c}\text { CsA } \\
\text { g. }\end{array}$ & $\begin{array}{l}\text { Cs } \\
\text { Mt. }\end{array}$ & $\begin{array}{l}\text { OCOR- } \\
\text { RÊNCIA }\end{array}$ \\
\hline Aberturas (Ab.) & 1 & 1 & 1 & 1 & 0 & 0 & 4 \\
\hline Aproveitamento de águas pluviais (Aap.) & 0 & 0 & 0 & 0 & 1 & 0 & 1 \\
\hline Coberturas (Cb.) & 0 & 1 & 0 & 0 & 0 & 0 & 1 \\
\hline Condições climáticas (Cc.) & 0 & 1 & 0 & 0 & 1 & 0 & 2 \\
\hline Acessos (Ac.) & 0 & 0 & 0 & 1 & 0 & 0 & 1 \\
\hline Tecnologias economizadoras (Te.) & 0 & 0 & 0 & 0 & 1 & 0 & 1 \\
\hline Espaçamento entre edifícios (Eef.) & 0 & 1 & 0 & 0 & 0 & 0 & 1 \\
\hline Entorno (Et.) & 1 & 1 & 1 & 0 & 0 & 0 & 3 \\
\hline Fonte de luz artificial (Fa.) & 0 & 1 & 1 & 0 & 0 & 0 & 2 \\
\hline Fonte de ruído externo (Fe.) & 1 & 0 & 0 & 0 & 0 & 0 & 1 \\
\hline Fonte de ruído interno (Fi.) & 1 & 0 & 0 & 0 & 0 & 0 & 1 \\
\hline Fonte de luz natural (Fn.) & 0 & 1 & 1 & 0 & 0 & 0 & 2 \\
\hline Geometria (Ge.) & 1 & 1 & 1 & 1 & 0 & 1 & 5 \\
\hline Infiltração de águas pluviais (Iap.) & 0 & 0 & 0 & 0 & 1 & 0 & 1 \\
\hline Materiais (Mt) & 1 & 1 & 1 & 1 & 1 & 1 & 6 \\
\hline Orientação (Ot.) & 1 & 1 & 1 & 0 & 0 & 0 & 3 \\
\hline Retenção de águas pluviais (Rap.) & 0 & 0 & 0 & 0 & 1 & 0 & 1 \\
\hline Topografia (Tp.) & 0 & 1 & 0 & 1 & 0 & 0 & 2 \\
\hline Volumetria (V1.) & 1 & 1 & 1 & 1 & 0 & 1 & 5 \\
\hline TOTAL & 8 & 12 & 8 & 6 & $\overline{6}$ & 3 & \\
\hline
\end{tabular}

Fonte: Brígitte (2013, p. 91).

Nota: Legenda:

Conforto acústico (Ac.);

Conforto térmico (Te.);

Conforto luminoso (Lm.);

Acessibilidade (Ac.);

Consumo de água (CsAg.);

Consumo de materiais (CsMt.).

Ocorrência: $0=$ não; $1=\operatorname{sim}$. 
Figura 5 - 0 modelo de informação integrado para múltiplos desempenhos

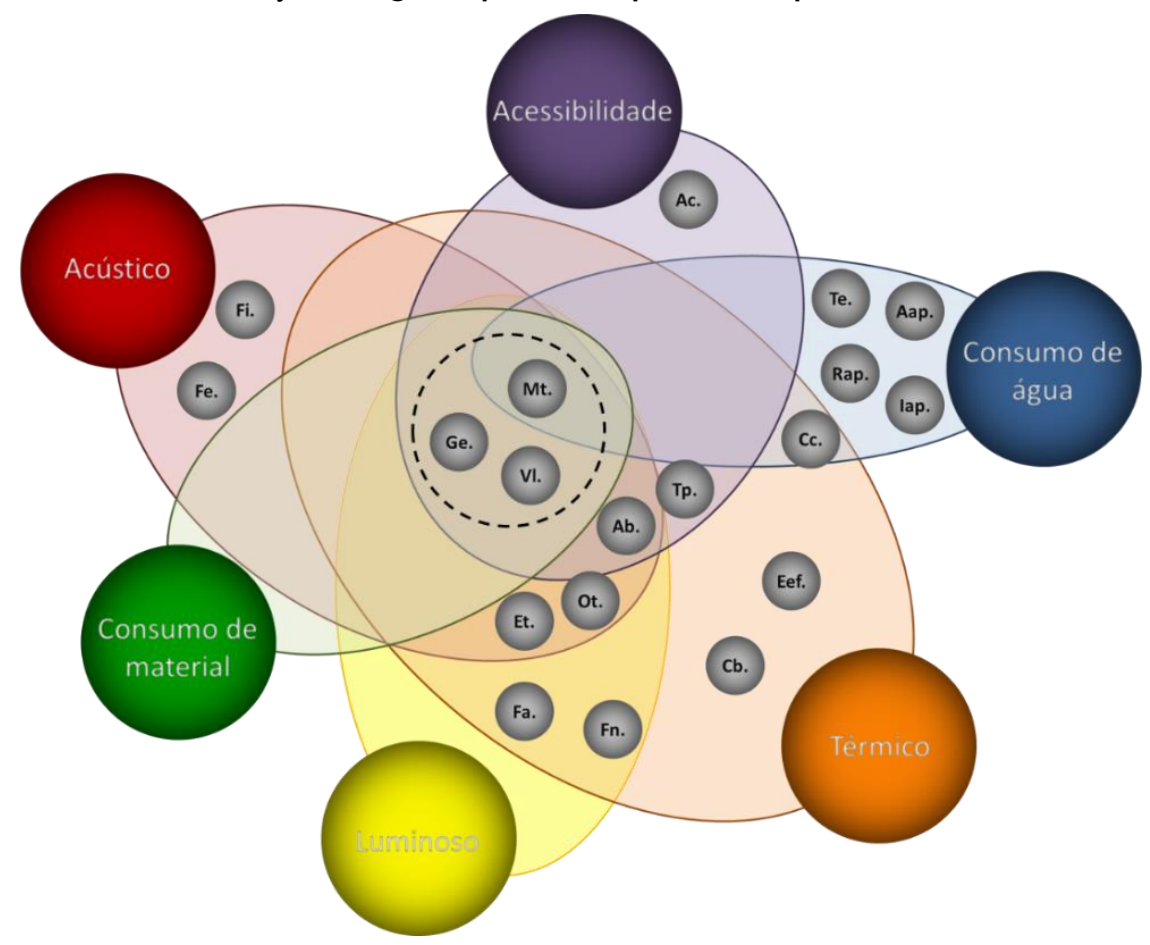

Fonte: Brígitte (2013, p. 95).

\section{Multidesempenho}

Avaliando-se em conjunto as observações dos especialistas, foi possível levantar a relação do que sofre influência e do que exerce influência, conforme a Tabela 2. Nessa tabela a coluna "Influência" apresenta o número de desempenhos influenciados, de modo que, quanto maior o número, maior a influência. Já a linha "Sofre influência de" apresenta através da maior numeração aquele que é mais influenciado. A partir dessa tabela tem-se o esquema de interferências apresentado pela Figura 6. Observase que, segundo os especialistas entrevistados, o desempenho acústico e o consumo de materiais são os que sofrem mais impacto em relação às decisões tomadas sobre outros desempenhos, enquanto o consumo de água pouco é influenciado ou influencia outro desempenho. Podemos também ressaltar a grande relação de interdependência das soluções.

Objetivando reduzir o número de retrabalhos e identificar um possível ordenamento de soluções em que o processo de projeto é sequencial e um especialista parte da solução de outro, buscou-se compreender a relação de influência entre os desempenhos de modo que estes pudessem ser sequenciados. Os resultados expostos sugerem uma possível metodologia baseada nas influências dos desempenhos, orientando uma sequência (do menos influenciado ao mais) para a realização das simulações, na tipologia estudada, conforme ilustra a Figura 7.

Entretanto, deve-se considerar que o ordenamento apresentado resulta de um contexto muito específico. Alterado o conjunto de especialistas envolvidos, o conjunto de desempenhos ou o tipo de projeto, a ordenação pode ser outra. A contribuição desta investigação está na forma apresentada de se ouvir os envolvidos e considerar suas percepções de influência sobre os demais, e de identificar os parâmetros de avaliação e o modelo integrado de informação. Essa dinâmica pode ser repetida em contextos diversos de projeto e apontar resultados diferentes. Entretanto, apontase a importância para a identificação dos parâmetros essenciais e compartilhados para a avaliação de desempenho, pois delimitam as interfaces de influência e demanda por decisão de projeto compartilhada. 
Tabela 2 - Interferências entre os desempenhos estudados

\begin{tabular}{l|c|c|c|c|c|c|c}
\hline & Ace. & Ac. & CsAg. & CsMt. & Lm. & Te. & Influência \\
\hline Acessibilidade (Ace.) & 0 & 1 & 0 & 1 & 1 & 1 & $\mathbf{4}$ \\
\hline Acústico (Ac.) & 1 & 0 & 0 & 1 & 1 & 1 & $\mathbf{4}$ \\
\hline Consumo de água (CsAg.) & 0 & 1 & 0 & 1 & 0 & 0 & $\mathbf{2}$ \\
\hline Consumo de materiais (CsMt.) & 1 & 1 & 1 & 0 & 1 & 1 & $\mathbf{5}$ \\
\hline Luminoso (Lm.) & 1 & 1 & 0 & 1 & 0 & 1 & $\mathbf{4}$ \\
\hline Térmico (Te.) & 1 & 1 & 0 & 1 & 1 & 0 & $\mathbf{4}$ \\
\hline Sofre Influência de & $\mathbf{4}$ & $\mathbf{5}$ & $\mathbf{1}$ & $\mathbf{5}$ & $\mathbf{4}$ & $\mathbf{4}$ & \\
\hline
\end{tabular}

Fonte: Brígitte (2013, p. 97).

Figura 6 - Relação de influência entre os desempenhos: no sentido anti-horário, do mais influenciado ao menos influenciado (esquerda); e relação de influência entre os desempenhos no sentido antihorário, do que mais exerce influência ao que menos exerce influência (direita)
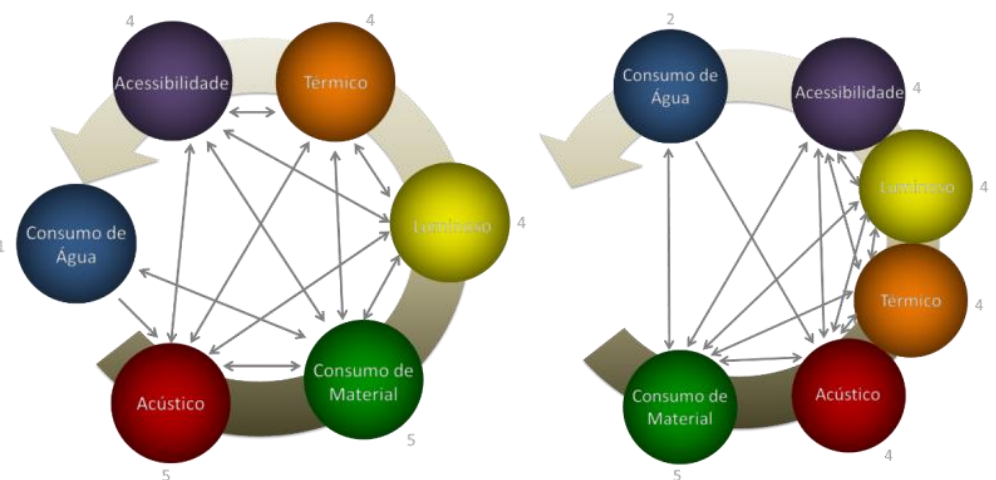

Fonte: Brígitte (2013, p. 98).

Figura 7 - Fluxo de projeto proposto pela pesquisa: sequência de simulações
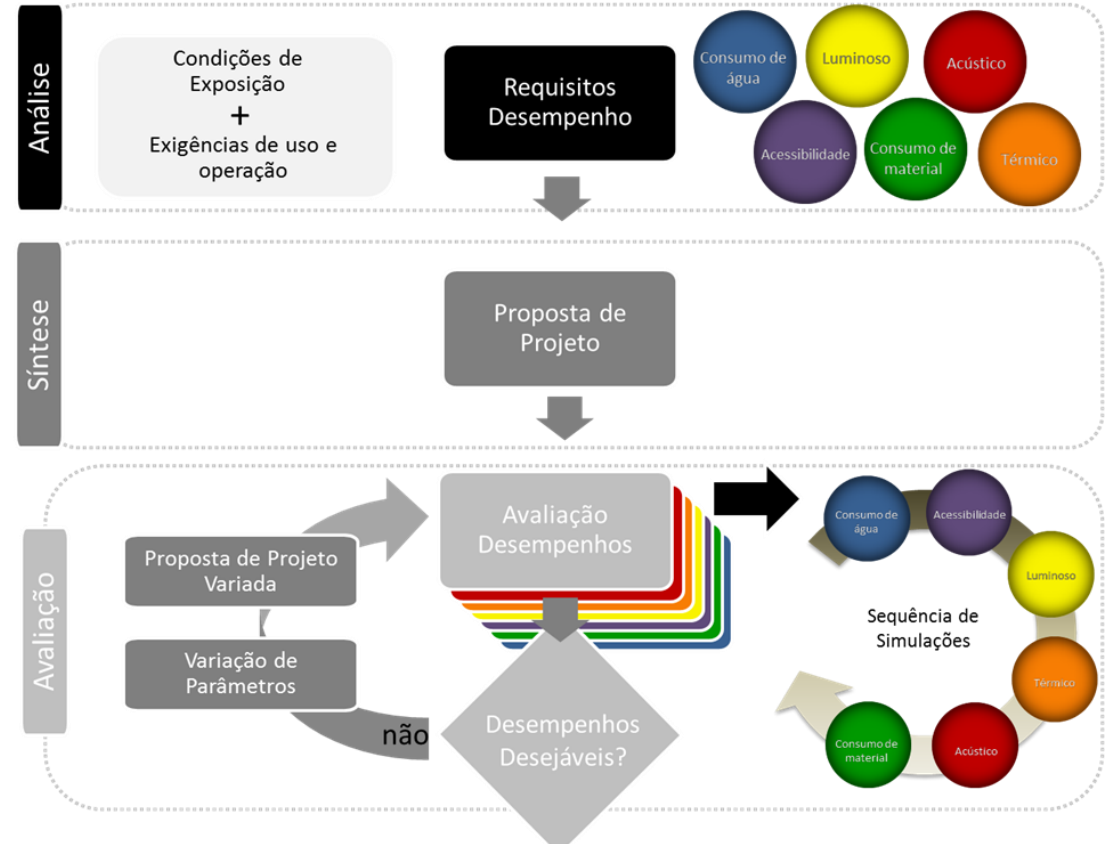

$\operatorname{sim}$

Detalhamento Projeto

Fonte: Brígitte (2013, p. 99). 


\section{Desempenho versus avaliação}

Avaliando-se em conjunto as observações dos especialistas, tem-se na Tabela 3 o levantamento dos métodos empregados na etapa de concepção. Pode-se observar que a maior parte dos desempenhos nesta fase é ainda avaliada através de processos analíticos e simulações físicas, com pouca interação por meio de ferramentas computacionais, apesar de haver conhecimento sobre elas nesta etapa. Os desempenhos que mais recorrem à avaliação, ainda na etapa de concepção, são os desempenhos térmico e luminoso, fato esse que observarmos também no levantamento, apresentado na Instrumentos de avaliação computacional de desempenho, para as características das simulações realizadas.

\section{Avaliação versus ferramenta computacional}

Apresentam-se através da Figura 8 as ferramentas de avaliação computacional do desempenho por especialidade na fase de concepção, citadas nas entrevistas. Apresentam-se também o escopo de cada desempenho para a aplicação da ferramenta e os objetivos a serem alcançados nesta etapa. O único desempenho para o qual não houve a identificação de ferramenta foi para a avaliação do consumo de água.

Diante da inexistência de ferramentas capazes de analisar simultaneamente diferentes desempenhos para a integração das análises com o auxílio de ferramentas computacionais, tornou-se necessário compor um macrofluxo, apresentado na Figura 9, da comunicação entre as ferramentas analisadas. A Figura 9 apresenta no eixo "y" o nível de detalhamento presente na etapa de aplicação das ferramentas, com a cor vermelha identifica as ferramentas de modelagem, e com a azul, de análise. Entretanto, ressaltamos que é necessário analisar a correta transferência das propriedades físicas e geométricas dos modelos durante a integração dessas ferramentas, uma vez que não faz parte desta pesquisa analisar criteriosamente a interoperabilidade. Destacamos apenas a ausência de comunicação entre as ferramentas de modelagem e os softwares Envest II e Vistoria Eletrônica, uma vez que os dados de entrada são feitos manualmente. Observamos ainda nessa ilustração a relação entre os formatos recorrentes no resultado dos questionários (DWG, DXF, 3DS) e a comunicabilidade entre as ferramentas, uma vez que aquelas que possuem maior relação (AutoCAD e SketchUp) apresentam tais formatos.

\section{Conclusão}

Os objetivos propostos para esta pesquisa foram alcançados nas seguintes medidas:

(a) os parâmetros de avaliação para cada tipo de simulação de desempenho estudado foram identificados (Tabela 1);

(b) os compartilhamentos desses parâmetros entre as simulações de desempenho analisadas também foram identificados (Figura 5);

(c) a ordenação de encadeamento sequencial de solução de projeto por desempenho foi identificada considerando o sequenciamento do desempeno menos influenciado pelos outros para aquele que é mais influenciado na percepção dos especialistas envolvidos no processo de projeto (Figura 7);

(d) caracterizaram-se as ferramentas de avaliação computacional dos desempenhos estudados para a fase de concepção (Figura 8); e

(e) elaborou-se um macrofluxo da comunicação entre as ferramentas (Figura 9).

Tabela 3 - Métodos de avaliação do desempenho do projeto na etapa de concepção

\begin{tabular}{l|c|c|c|c|c|c|c}
\hline & Ace. & Ac. & CsAg. & CsMt. & Lm. & Te. & Métodos \\
\hline Análise analítica (cálculos) & 0 & 1 & 1 & 1 & 1 & 1 & $\mathbf{5}$ \\
\hline Análise do projeto (visual) & 1 & 0 & 0 & 0 & 1 & 1 & $\mathbf{3}$ \\
\hline $\begin{array}{l}\text { Ferramenta de simulação } \\
\text { (através de modelos físicos) }\end{array}$ & 1 & 0 & 0 & 0 & 1 & 1 & $\mathbf{3}$ \\
\hline $\begin{array}{l}\text { Ferramenta de simulação (conhece) } \\
\text { (através de modelos computacionais) }\end{array}$ & 0 & 1 & 0 & 1 & 1 & 1 & $\mathbf{4}$ \\
\hline $\begin{array}{l}\text { Ferramenta de simulação (utiliza) } \\
\text { (através de modelos computacionais) }\end{array}$ & 0 & 0 & 0 & 0 & 0 & 0 & $\mathbf{0}$ \\
\hline Métodos utilizados/desempenho & $\mathbf{2}$ & $\mathbf{2}$ & $\mathbf{1}$ & $\mathbf{2}$ & $\mathbf{4}$ & $\mathbf{4}$ & \\
\hline
\end{tabular}

Fonte: Brígitte (2013, p. 100). 
Figura 8 - Escopos, ferramentas e objetivos da simulação

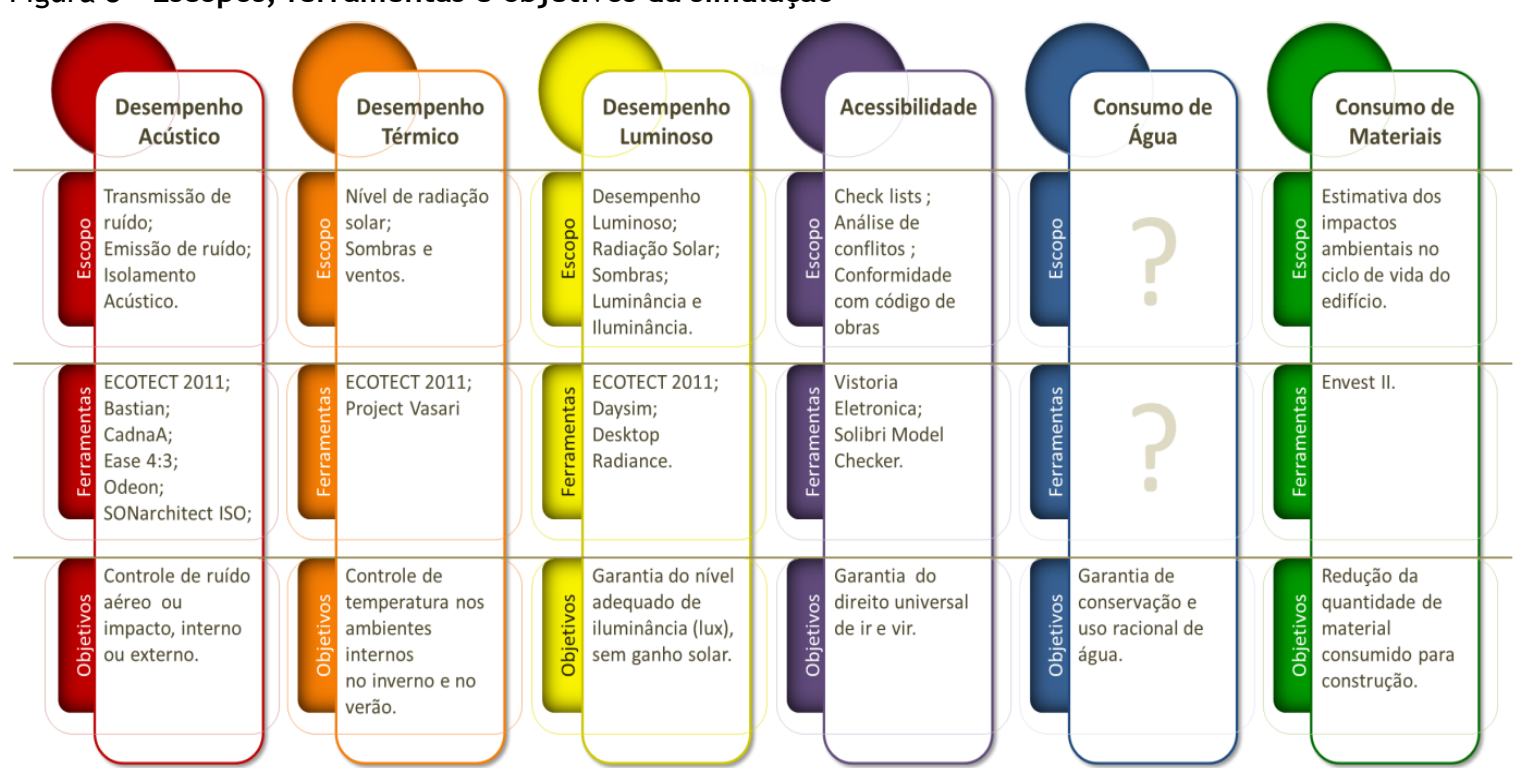

Fonte: Brígitte (2013, p. 101).

Figura 9 - Macrofluxo da comunicação entre as ferramentas resultantes do levantamento

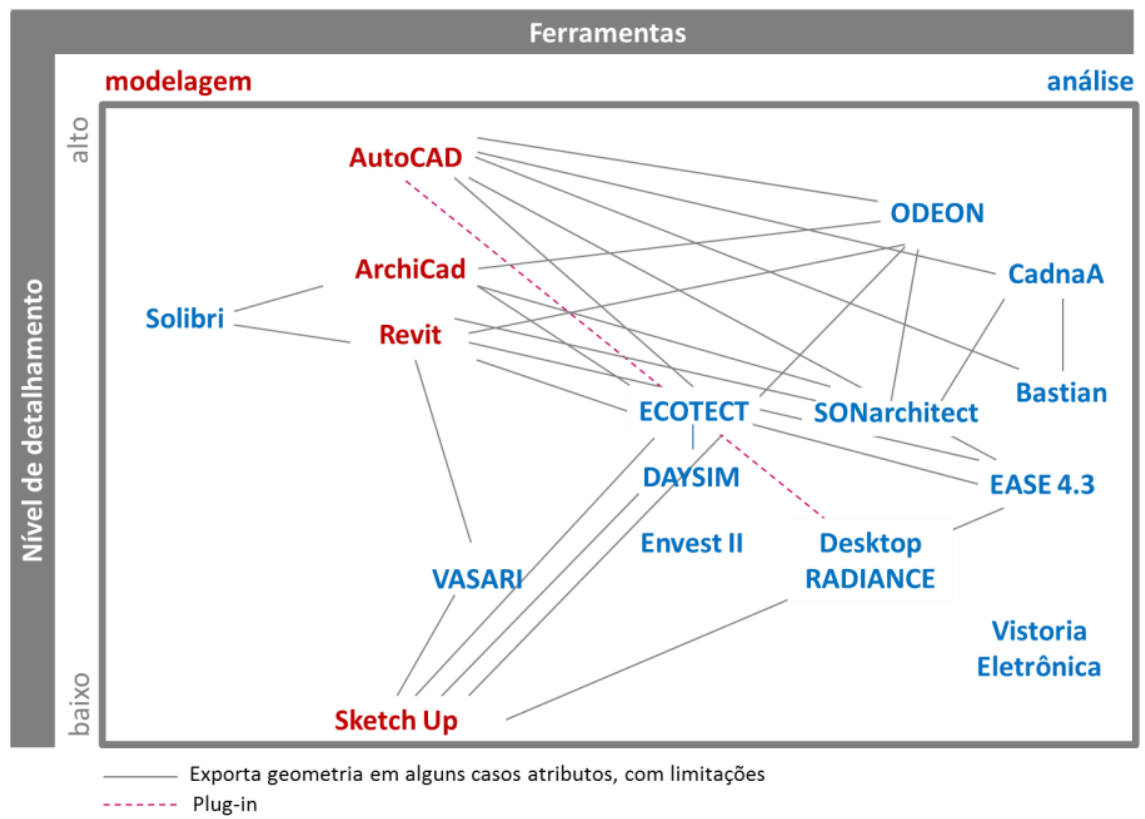

Fonte: Brígitte (2013, p. 107).

Esses resultados abrangem a integração das análises de diferentes desempenhos através do uso da modelagem de informação e simulação computacional na etapa de concepção arquitetônica no projeto de implantação de conjuntos habitacionais. $\mathrm{O}$ enfoque esteve sob seis áreas: conforto térmico, conforto acústico, conforto luminoso, conservação de recursos materiais, conservação de água e acessibilidade. Através do estudo de campo foi possível elucidar o modelo de representação analítica e identificar os parâmetros que entram em confronto direto por serem compartilhados por um ou mais desempenhos. Identificaram-se nesse contexto o modelo de informação mínimo e o mais reutilizado entre simulações envolvendo os materiais, a geometria e a volumetria. Nesse caso se observa a necessidade de antecipar a especificação de materiais, o que muitas vezes é decidido apenas em fases mais avançadas do projeto, como no detalhamento. Pode-se ainda analisar a influência interdesempenhos, que resulta na proposição de 
uma metodologia que descreve o sequenciamento das simulações (Figura 7).

O modelo de informação integrado de desempenhos (Figura 5) pôde auxiliar no mapeamento dos impactos da variação de determinado parâmetro, coincidente ou não, em diferentes simulações durante o processo de decisão, além de orientar a criação do modelo único, capaz de ser submetido a diferentes simulações. A utilização do modelo único para as simulações diminui o risco de perder soluções adotadas durante $\mathrm{o}$ processo e da falta de identificação da influência das decisões tomadas diante do conjunto do projeto. Entretanto, constatou-se que o modelo de informação não é único durante o fluxo de informação para análise de desempenhos, mas existe um nível de informação mínimo que foi identificado nesta pesquisa: geometria, volumetria e materiais.

O estudo de campo permitiu criar uma estrutura conceitual da hipótese, caracterizando as informações agregadas ao modelo e explicitando seus parâmetros, influências e sequenciamento das simulações. Tem-se como ressalva não poder afirmar que o sequenciamento proposto pode ser reaplicado para qualquer tipologia de projeto e conjunto de desempenhos. Deve-se considerar que o ordenamento obtido resulta de um contexto muito específico. Como já mencionado, mudado o conjunto de especialistas envolvidos, o conjunto de desempenhos ou o tipo de projeto, a ordenação pode ser outra, sendo essa uma característica inerente às soluções arquitetônicas. A contribuição desta investigação reside na forma de se considerarem percepções de especialistas de desempenho e de se identificarem os parâmetros de avaliação e modelo integrado de informação correspondente. Destaca-se a importância para a identificação dos parâmetros essenciais e compartilhados para a avaliação de desempenho em ferramental BIM, pois delimitam as interfaces entre especialistas que demandam uma decisão consensual.

O levantamento realizado com especialistas da área de conforto indica que as simulações de desempenho são mais utilizadas para ambientes internos nas tipologias residencial, institucional e comercial, e que os desempenhos mais avaliados são o luminoso, o térmico e o de eficiência energética. Esse perfil foi confirmado entre os especialistas entrevistados. Além disso, entre eles se observou que o desempenho em projeto ainda é avaliado através de processos analíticos e simulações físicas, com pouca interação por intermédio de ferramentas computacionais, apesar de haver conhecimento sobre elas nessa etapa. Esse cenário pode advir da barreira resultante da baixa interoperabilidade entre as ferramentas de modelagem e as análises disponíveis. Outro impedimento ao uso de ferramentas computacionais de análise de desempenho, apesar do conhecimento, é a complexidade inerente dessas ferramentas, que encontra como contrapartida o desejo por simplicidade por parte dos projetistas.

Dessa maneira, este trabalho, além de contribuir para a caracterização do modelo de informação para uso de diferentes ferramentas de simulação durante a etapa de concepção da implantação de HIS, impulsiona o aperfeiçoamento do uso de Building Modeling Information (BIM) em projetos e o aumento do uso de ferramentas de simulação e tecnologia da informação na construção na etapa de concepção do projeto.

\section{Referências}

ALUCCI, M. P. TAO: uma metodologia para a implantação de edificação: enfase no desempenho térmico, acústico e energético. 2007. 145 f. Tese (Livre docência) - Faculdade de Arquitetura e Urbanismo, Universidade de São Paulo, São Paulo, 2007.

ANDRADE, M. L. V. X. de; RUSCHEL, R. C. Interoperabilidade de Aplicativos BIM Usados em Arquitetura Por Meio do Formato IFC. Gestão \& Tecnologia de Projetos, v. 4, n. 2, p. 76-111, dez. 2009.

ATTIA, S. Building Performance Simulation

Tools: selection criteria and user survey. Louvain La Neuve: Université Catholique de Louvain, 2010. (Research Based Report).

ATTIA, S. et al. Architect Friendly: a comparison of ten different building performance simulation tools. In: BI-ANNUAL INTERNATIONAL BUILDING PERFORMANCE SIMULATION ASSOCIATION CONFERENCE, 11., Glasgow, 2009. Proceedings... Glasgow: IBPSA, 2009.

BARTAK, M. et al. An Approach to Teaching and Research of Simulation for Environmental Engineering Design. In: INTERNATIONAL CONFERENCE ON ADVANCED ENGENEERING DESIGN, 3., Prague, 2003. Proceedings... Prague: Czech Technical University, 2003.

BRÍGITTE, G. T. N. Integração de Desempenho na Avaliação de Projeto: modelo de informação e simulação computacional na etapa de concepção. 2013. 225 f. Dissertação (Mestrado em Engenharia Civil) - Faculdade de Engenharia Civil, Arquitetura e Urbanismo, Universidade Estadual de Campinas, Campinas, 2013. 
CHWIF, L.; MEDINA, A. C. Modelagem e Simulação de Eventos Discretos: teoria e aplicações. 3. ed. São Paulo: Leonardo Chwif, 2010.

CLARKE, J. A.; HENSEN, J. L. M. Integrated Building Performance Simulation: progress, prospects and requirements. Building and Environment, v. 91, p. 294-306, nov. 2015.

CRAWLEY, D. B. Contrasting the Capabilities of Building Energy Performance Simulation Programs. Building and Environment, v. 43, n. 4, p. 661-663, apr. 2008.

EASTMAN, C. et al. Bim Handbook: a guide to building information modeling for owners, managers, designers, engineers and contractors. Hoboken: John Wiley \& Sons, 2008.

FABRÍCIO, M. M. Projeto Simultâneo na Construção de Edifícios. São Paulo, 2002. Tese (Doutorado em Enge) - Escola Politécnica, Universidade de São Paulo, São Paulo, 2002.

GIANNANTONI, C. et al. Multicriteria Approach for the Improvement of Energy Systems Design. Energy, v. 30, n. 10, p. 1989-2016, nov. 2005.

GIBSON, E. J. (Coord.). Working With the Performance Approach in Building. Rotterdam: CIB W060, 1982. (CIB Report, Publication 64).

HOLM, D. Building Thermal Analyses: what the industry needs: the architect's perspective.

Building and Environment, v. 28, n. 4, p. 405407, oct. 1993.

HUI, S. C. M. Simulation Based Design Tools for Energy Efficient Buildings in Hong Kong. Hong Kong: Department of Architecture, University of Hong, 1998.

JU, C.; NING, Y.; PAN, W. A Review of Interdependence of Sustainable Building. Environmental Impact Assessment Review, v. 56, p. 120-127, oct. 2016.

KALAY, Y. E. Performance-Based Design. Automation in Construction, v. 8, n. 4, p. 395409, apr. 1999.

LOBOS, D.; TREBILCOCK, M. Building Performance Information and Graphs Approach for the Design of Floor Plans. Arquitetura Revista, v. 10, n. 1, p. 23-40, jan./june. 2014.

MALKAWI, A. M. Performance Simulation: research and tools. In: KOLAREVIC, B.; MALKAWI, A. M. (Eds.). Performative Architecture: beyond instrumentality. New York: Spon Press, 2005.
MALKAWI, A. M.; AUGENBROE, G. Advanced Building Simulation. New York: Spon Press, 2004.

MARSH, A. J. Performance Analysis and Conceptual Design. Perth, 1997. Thesis (PhD.) University of Western Australia, School of Architecture and Fine Arts, Perth, 1997.

MATHEWS, E. H.; RICHARDS, P. G. An Efficient Tool for Future Building Design. Building and Environment, v. 28, n. 4, p. 409417, oct. 1993.

MELHADO, S. B. Gestão, Cooperação e Integração Para Um Novo Modelo Voltado à Qualidade do Processo de Projeto na Construção de Edifícios. São Paulo, 2001. Tese (Livre-Docência) - Escola Politécnica, Universidade de São Paulo, São Paulo, 2001.

NASCIMENTO, L. A. do; SANTOS, E. T. A Indústria da Construção na Era da Informação. Ambiente Construído, Porto Alegre, v. 3, n. 1, p. 69-81, jan./mar. 2003.

NAYLOR, T. H. et al. Computer Simulation Techniques. New York: John Wiley \& Sons, 1966.

PAPAMICHAEL, K. M. Design Process and Knowledge Possibilities and Limitations of Computer-Aided Design. Berkeley, 1991. Thesis (Ph.D.) - University of California, Berkeley, 1991.

PAZLAR, T.; TURK, Z. Interoperability in Practice: geometric data exchance using the IFC standard. ITcon, v. 13, special issue case studies of BIM use, p. 362-380, 2008.

PETERSEN, S.; SVENDSEN, S. Method and Simulation Program Informed Decisions in the Early Stages of Building Design. Energy and Buildings, v. 42, n. 7, p. 1113-1119, jul. 2010.

ROMANO, F. V. Modelo de Referência Para o Gerenciamento do Processo de Projeto Integrado de Edificações. Florianópolis, 2003. 381 f. Tese (Doutorado em Engenharia Civil) Engenharia de Produção, Universidade Federal de Santa Catarina, Florianópolis, 2003.

RUSCHEL, R. C. Conjunto da Produção Científica. Campinas, 2009. 66 f. Conjunto da Produção Científica (Livre Docência) - Faculdade de Engenharia Civil, Arquitetura e Urbanismo, Universidade Estadual de Campinas, Campinas, 2009.

SMITH, D. K.; TARDIF, M. Building

Information Modeling: a strategic implementation guide for architects, engineers, constructors, and real estate asset managers. Hoboken: John Wiley \& Sons, 2009. 
SOEBARTO, V. I.; WILLIAMSON, T. J. MultiCriteria Assessment of Building Performance Theory and Implementation. Building and Environment, v. 36, n. 6, p. 681-690, jul. 2001.

STRUCK, C.; HENSEN, J. On Supporting Design Decisions in Conceptual Design Addressing Specification Uncertainties Using Performance Simulation. In: BI-ANNUAL INTERNATIONAL BUILDING PERFORMANCE SIMULATION ASSOCIATION CONFERENCE, 10., Beijing, 2007. Proceedings... Beijing: IBPSA, 2007.

WESTPHAL, F. S. Análise de Incertezas e de Sensibilidade Aplicadas à Simulação de Desempenho Energético de Edificações Comerciais. Florianópolis, 2007, 131 f. Tese (Doutorado em Engenharia Civil) - Universidade Federal de Santa Catarina, Florianópolis, 2007.
WILLIAMS, B. K.; SAWYER. S. C. Using Information Technology: a practical introduction to computers and communications. 7. ed. Irwin: McGraw-Hill, 2007.

WOOD, H.; GIDADO, K. Project Complexity in Construction. In: THE CONSTRUCTION AND BUILDING RESEARCH CONFERENCE OF THE ROYAL INSTITUTION OF CHARTERED SURVEYORS - COBRA, Dublin, 2008. Proceedings... Dublin: Cobra, 2008.

YEZIORO, A. et al. An Applied Artificial Intelligence Approach Towards Assessing Building Performance Simulation Tools. Energy and Buildings, v. 40, n. 4, p. 612-620, 2008.

Revista Ambiente Construído

Associação Nacional de Tecnologia do Ambiente Construído

Av. Osvaldo Aranha, $99-3^{\circ}$ andar, Centro

Porto Alegre - RS - Brasil CEP $90035-190$

Telefone: +55 (51) 3308-4084

Fax: +55 (51) 3308-4054

www.seer.ufrgs.br/ambienteconstruido

E-mail: ambienteconstruido@ufrgs.br 